\title{
Desain Barge sebagai Alternatif Pengganti Jetty untuk Sarana Bongkar Muat Kapal Tanker
}

\author{
M. Hafiz Nurwahyu Aliffrananda dan Wasis Dwi Aryawan \\ Departemen Teknik Perkapalan, Fakultas Teknologi Kelautan, \\ Institut Teknologi Sepuluh Nopember (ITS) \\ e-mail:wasis@na.its.ac.id
}

\begin{abstract}
Abstrak-Pada umumnya proses bongkar muat kapal tanker berlangsung di dermaga dengan menghubungkan selang yang ada didermaga dengan peralatan bongkar muat yang ada pada kapal tanker yaitu cargo manifold. Akan tetapi permasalahan muncul ketika kapal-kapal tanker tersebut tidak dapat merapat ke dermaga diakibatkan karena sarat kapal yang terlalu besar ataupun karena lautan di sekitar dermaga memiliki kedalaman air yang kurang sehingga diperlukan jetty sebagai sarana bongkar muat akan tetapi harga pembangunan jetty yang mahal dapat mengurangi pendapatan dermaga sehingga dibutuhkan barge untuk menggantikannya. Dalam permasalahan ini metode yang digunakan adalah intuitive design method yang diawali dengan menganalisa kondisi perairan sekitar dermaga, kemudian menganalisis payload yang merupakan peralatan bongkar muat apa saja yang harus ada pada barge shingga didadapatkan ukuran utama dari barge serta mendesain sistem kerja dari penyaluran muatan dari kapal tanker ke dermaga sehingga barge dapat dijadikan alternatif sarana bonkar muat pengganti jetty untuk kapal tanker. Dari desain yang telah dilakukan didapatkan ukuran utama barge yaitu LOA $43.2 \mathrm{~m}$, Lebar $16 \mathrm{~m}$, Tinggi 3.6 m dan draught 2.7 meter. Harga pembangunan dari barge adalah sebesar Rp53,978,058,950.86. Harapannya dengan adanya sarana pengganti jetty dengan barge dapat mempercepat proses bongkar muat khususnya untuk kapal tanker dan mengurangi biaya dari pembuatan sarana dan prasarana dermaga.
\end{abstract}

Kata Kunci-barge, bongkar muat, dermaga,jetty, tanker.

\section{PENDAHULUAN}

$\mathrm{I}^{\mathrm{s}}$ NDONESIA merupakan negara kepulauan yang besar dengan laut seluas 5.8 juta $\mathrm{km}$ persegi terdiri dari wilayah teritorial 3.2 juta $\mathrm{km}$ persegi dan wilayah ZEE (Zona Ekonomi Ekslusif) 2.7 juta km persegi serta memiliki 4 diantara 10 lokasi paling strategis didunia untuk menjadi pusat kegiatan industri dan perdaganagn yaitu Selat Malaka, Selat Sunda, Selat Lombok dan Selat Makassar menjadikan Indonesia sebagai calon poros maritim dunia. Selain itu jumlah armada kapal yang berlayar di area perairan Indonesia pada tahun 2018 cukup banyak terutama kapal tanker. Dari data yang dimiliki oleh Marine Traffic menujukan terdapat 563 kapal Tanker yang sedang beroperasi di Laut Jawa, Laut Banda, Laut Timor, Laut Arafura dan Selat Makasar. Selain kapal kapal tanker tersebut kapal kapal tanker yang di miliki PT. Pertamina sebagai Badan Usaha Milik Negara sendiri tergolong cukup besar yaitu sebanyak 237 kapal tanker dengan rincian 77 kapal merupakan milik sendiri dan sisanya merupakan kapal sewa. Akibat dari banyaknya jumlah kapal tanker tersebut mengakibatkan kebutuhan terkait pelayanan kapal dan aktivitas kapal tanker membutuhkan sarana dan prasarana yang memadai untuk memfasilitasi dan mempercepat aktifitas kapal terutama dalam aktifitas bongkar muat (loading unloading) dan pengisisan bahan bakar. Hal ini dibutuhkan untuk mewujudkan Indonesia menjadi Poros
Maritim Dunia yaitu menjadi sebuah negara maritim yang maju, berdaulat, mandiri, kuat, serta mampu memberikan konstribusi positif bagi keamanan dan perdamaian kawasan dan dunia sesuai kepentingan nasional sebagai perwujudan dari Visi Geomaritim Indonesia [1].

Pada umumnya proses bongkar muat kapal tanker berlangsung di dermaga dengan menghubungkan selang yang ada di dermaga dengan peralatan bongkar muat yang ada pada kapal tanker yaitu cargo manifold. Akan tetapi permasalahan muncul ketika kapal-kapal tanker tersebut tidak dapat merapat ke dermaga diakibatkan karena sarat kapal yang terlalu besar ataupun karena lautan di sekitar dermaga memiliki kedalaman air yang kurang sehingga diperlukan peralatan tambahan untuk membantu dan mempermudah proses bongkar muat bagi kapal kapal tanker tersebut. Biasanya peralatan tambahan tersebut berupa bangunan permananen tambahan pada struktur dermaga yang biasa disebut dengan jetty.

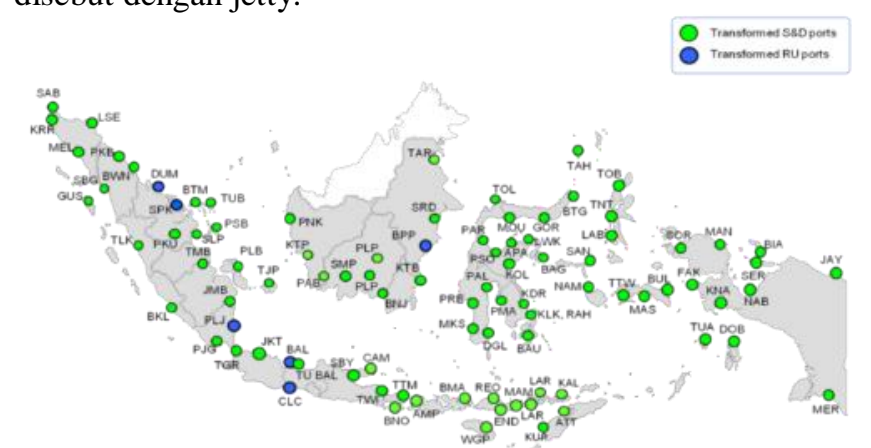

Gambar 1. Penyebaran 107 Pelabuhan Migas di Indonesia.

Di Indonesia sendiri khususnya pelabuhan pelabuhan migas PT. Pertamina jetty menjadi kebutuhan primer pelabuhan tersebut karena kebanyakan armada kapal milik PT. Pertamina merukapan kapal tanker dan pelabuhan migas PT. Pertamina jumlahnya tidak sedikit, dapat dilihat pada gambar 1.1 terdapat 107 pelabuhan yaitu 6 pelabuhan kilang minyak yang ditandai dengan dot atau titik berwarna biru dan 101 pelabuhan pemasaran dengan yang ditandai dengan warna hijau dengan pergerakan kapal setiap tahunnya kurang lebih mencapai 30000 unit yang tersebar di seluruh Indonesia dan sebagian besar dermaga tersebut menggunakan jetty sebagai sarana bongkar muat kapal tanker [1].

Akan tetapi pembangunan jetty pada dermaga memakan banyak biaya karena struktur jetty yang cukup panjang dan pemasangan pondasi bagi jetty di dalam laut yang susah menyebabkan biaya pembangunannya menjadi besar. Selain itu kelemahan lain dari adanya penggunaan jetty adalah adanya pendangkalan sehingga perlu dilaksanakan pengerukan (dredging) dengan kata lain terdapat penambahan biaya operasional berupa pengerukan sedimentasi. 
Kelemahan lainnya, karena kapal tanker memiliki nilai Coeficient Block (Cb) yang besar sehingga mengurangi Maneuverability menyebabkan kapal tanker sulit bersandar ke ujung Jetty dan kadang terjadi kecelakaan yaitu kapal menubruk Jetty. Oleh karena itu diperlukan alternative lain untuk melakukan proses bongkar muat (loading unloading) kapal tanker yaitu dengan menggunakan barge yang akan menyalurkan selang-selang yang akan digunakan untuk melakukan proses loading dan unloading dengan harapan dapat mempercepat layanan bongkar muat, percepatan pengisian bahan bakar dan mereduksi biaya pembangunan sarana untuk pelayanan kapal tanker.

\section{TINJAUAN PUSTAKA}

\section{A. Barge}

Barge atau dalam bahasa Indonesia lebih sering disebut Tongkang atau Ponton adalah suatu jenis kapal yang dengan lambung datar atau suatu kotak besar yang mengapung, yang biasanya digunakan untuk mengangkut barang dan ditarik dengan kapal tunda atau digunakan untuk mengakomodasi pasang-surut seperti pada dermaga apung. Tongkang sendiri pada umumnya tidak memiliki sistem pendorong (propulsi) akan tetapi di era sekarang banyak tongkang yang memiliki sistem propulsi sendir yang biasanya disebut dengan Self Propelled Barge. Pembuatan kapal tongkang juga berbedadengan kapal pada umumnya karena hanya konstruksi saja, tanpa sistem seperti kapal pada umumnya, sistem yang dimaksud disini adalah sistem perkapalan yang meliputi perpipaan, sistem ballast, dasn sistem sistem lainnya yang ada di kapal. Tongkang sendiri umumnya digunakan untuk mengangkut muatan dalam jumlah yang besar seperti kayu, batubara, pasir dan lain-lain.

\section{B. Kapal Tanker}

Kapal pengangkut muatan cair atau biasa disebut kapal tanker merupakan kapal yang dirancang atau didesain khusu untuk membawa muatan dalam wujud cairan. Kapal Tanker pertama kalai digunakan untuk membawa minyak bahan bakar dari kilang minyak ke konsumen ataupun dari tempat pengeboran minyak ke kilang minyak dalam industri minyak. Kapal tanker sendiri sekarang memiliki beberapa macama muatan yang dibawa seperti kapal tanker minyak (Oil Tanker), kapal tanker pembawa bahan kimia (Chemical Tanker), dan pengangkut LNG (LNG Tanker). Diantara berbagai jenis kapal tanker ada yang didesain dengan ukuran yang saagat besar atau biasa disebut dengan supertanker.

\section{Bongkar Muat Kapal Tanker}

Untuk melakukan proses bongkar muat, digunakan peralatan khusu untuk menangani muatan curah cair yaitu pipa, dan pompa yang digunakan sebagai alat transportasi bagi muatan tanker untuk disalurkan ke kilang minyak yang ada di dermaga. akan tetapi tidak semua kapal tanker dapat bersandar di dermaga sehingga dibutuhkan struktur tambhan pada dermaga atau struktur tambahan yang dipasang pada daerah dermaga untuk membantu bongkar muat kapal tanker yang tidak dapat bersandar di dermaga. Bergantung pada struktur apa yang digunakan sistem yang digunakan dalam melakukan bongkar muat pun juga berbeda. Selain itu ada juga kapal tanker yang melakukan bongkar muat ditengah laut dengan menggunakan shuttle tanker. Sistem bongkar muat ini disesuaikan dengan kondisi pada saat bongkar muat, yang meliputi ukuran kapal, fasilitas dermaga, dll. Berikut sistem bongkar muat kapal tanker.

\section{1) Dermaga Dolphin}

Dermaga dolphin merupakan struktur tambahan pada dermaga yang dikhusukan untuk mooring kapal kapal dengan ukuran besar yang dapat bersandar di dermaga secara langsung karena kedalaman air di dermaga yang besar sehingga memungkinkan kapal untuk bersandar di tepi dermaga. dermaga ini terdiri dari 3 komponen yaitu jetty dengan ukuran kecil, breasting dolphin, dan mooring dolphin. Di pulau Sambu di daerah Batam ada dermaga jenis ini dengan kapasitas kapal 100.000 DWT, dengan biaya pembangunannya mencapai Rp. 575.570.947.452,00 [2], sehingga dapat di estimasi untuk kapal berukuran 17.500 DWT biaya pembagunan dermaganya kira kira mencapai Rp. 100.724.915.804,00.

\section{2) Dermaga Jetty}

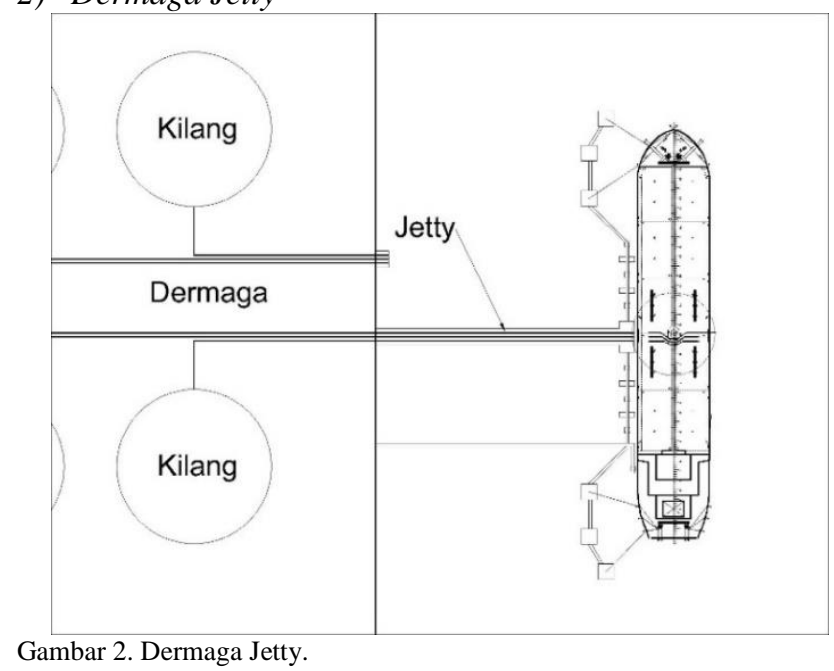

Jetty ini membentang sepanjang beberapa $\mathrm{km}$ dari daratan pelabuhan tergantung kondisi dari perairan yang ada didaerah dermaga, jetty yang cukup panjang biasanya karena daerah perairan sekitar dermaga yang dangkal sehingga kapal kapal berukuran besar tidak dapat bersandar secara langsung di pelabuhan. Selain itu ada hal lain yang menyebabkan jetty yang panjang, biasanya daerah dermaga tidak hanya diperuntukkan untuk bongkar muat kapal besar seperti tanker, tetapi terdapat kapal kapal penyeberangan dan kapal kapal lainnya. Karena bongkar muat tanker merupakan aktifitas yang cukup berbahaya sehingga jetty dibuat cukup panjang agar kapal-kapal yang lain tidak terpengaruh oleh bahaya dari bongkar muat kapal tanker [3].

\section{3) Single Point Mooring (SPM)}

Single point mooring (SPM) yang ditunjukkan pada gambar 7 adalah pelampung apung / jangkar di lepas pantai untuk memungkinkan penanganan kargo cair seperti produk minyak bumi untuk kapal tanker. SPM terutama digunakan di area di mana fasilitas khusus untuk memuat atau menurunkan muatan cair tidak tersedia. SPM terletak pada jarak beberapa kilometer dari fasilitas pantai dan terhubung menggunakan pipa bawah laut dan sub-minyak, fasilitas tambat satu titik (SPM) ini bahkan dapat menangani kapal dengan kapasitas besar seperti VLCC [4].

\section{4) Tandem Offloading}

Tandem loading adalah posisi kapal tanker yang menjaga jarak agak jauh di belakang FPSO, misalnya $80 \mathrm{~m}$. Kedua kapal secara fisik terhubung dengan hawser dan selang pembongkaran untuk mentransfer minyak kargo dari FPSO 
ke kapal tanker [5].

5) Ship to Ship Loading

Kapal-kapal seperti kapal oil tanker dan gas carrier yang membawa muatan dalam jumlah besar tidak harus dibongkar atau di unloading hanya dalam satu pelabuhan tetapi di beberapa pelabuhan yang berbeda. Bahkan beberapa operator seperti VLCC dan ULCC yang berukuran besar tidak dapat berlabuh di pelabuhan atau dermaga untuk operasi bongkar muat karena terbatasnya kedalaman air karena sarat kapal yang terlalu besar. Dalam kondisi seperti itu bongkar muat kapal ke kapal digunakan [6].

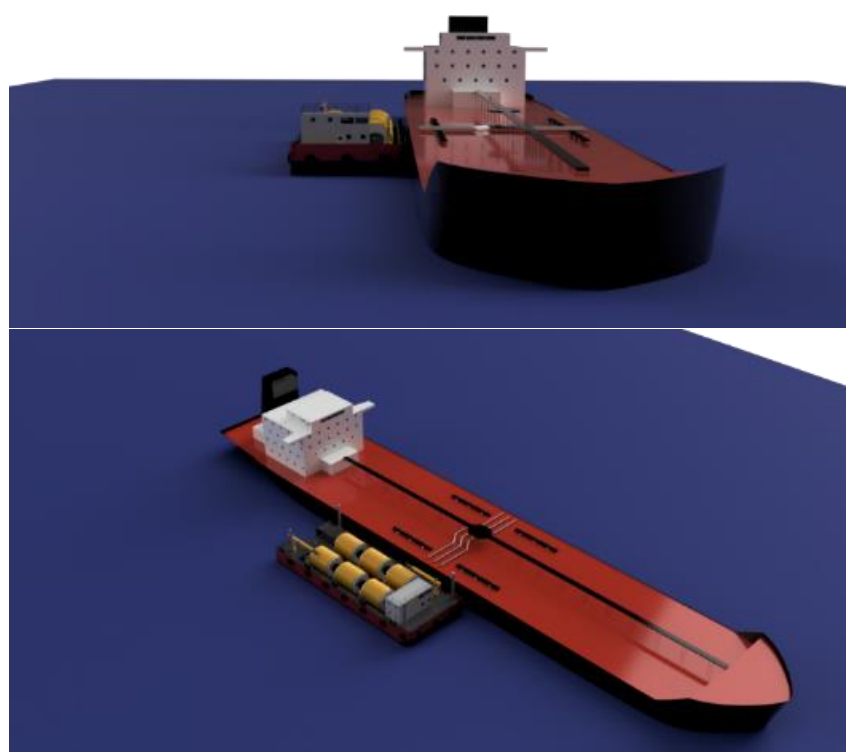

Gambar 3. Ship to Ship Offloading.

\section{METODOLOGI}

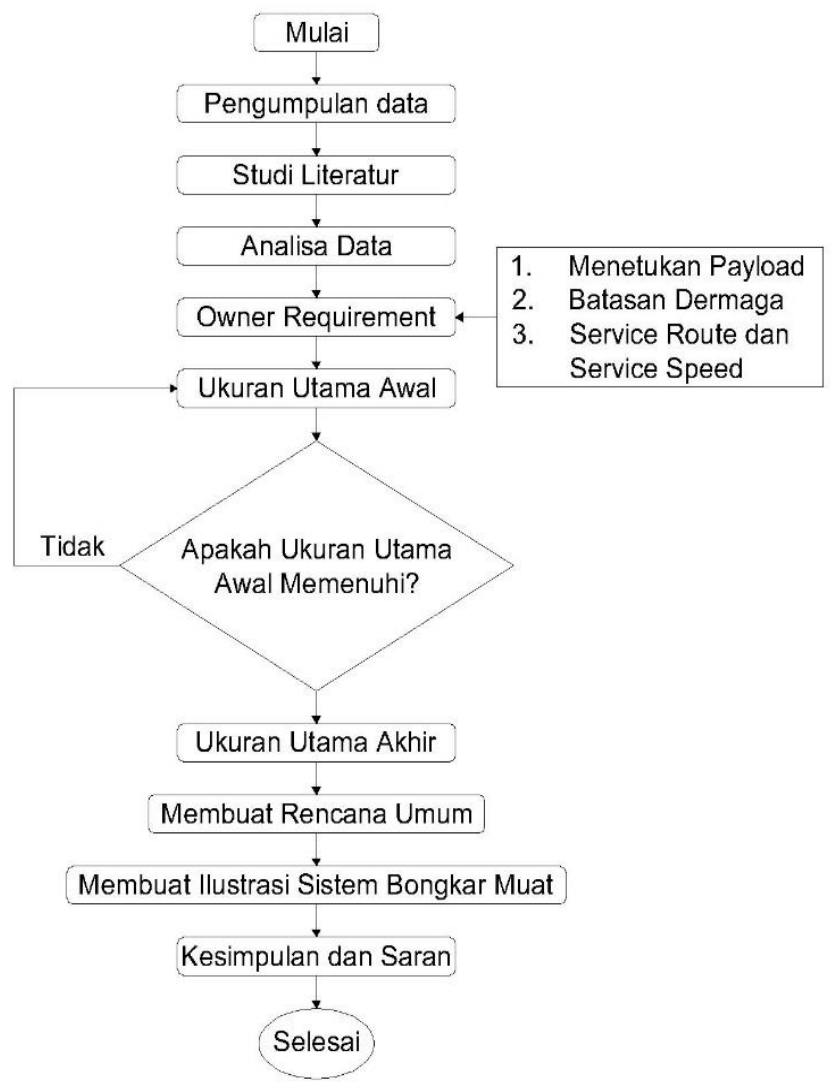

Gambar 4. Diagram Alir Proses Desain.

\section{ANALISIS TEKNIS DAN BIAYA PEMBANGUNAN}

\section{A. Owner Requirement}

Dalam mendesain sebuah kapal terdapat ketentuan ketentuan yang dijadikan acuan agar produk kapal yang didesain memiliki tujuan yang diinginkan oleh pemilik kapal. Ketentuan ketentuan ini tercantum dalam Owner Requirement. Owner requirement merupakan kumpulan ketentuan yang berasal dari pemilik kapal yang diberikan kepada desainer untuk dijadikan acuan dalam mendesain sebuah kapal, atau dalam tugas akhir ini adalah barge yang akan di desain. Sesuai dari fungsi dari barge yang akan didesain yaitu menggantikan fungsi dari jetty. Maka owner requirement dari barge meliputi peralatan bongkar muat tanker, jarak daerah yang akan di cover oleh barge serta perelengkapan mooring dari barge.

Tabel 1.

Owner Requirement

Owner Requirement

\begin{tabular}{lcc}
\multicolumn{3}{c}{ Owner Requirement } \\
\hline Ship Type & \multicolumn{2}{c}{ Barge } \\
Berat Peralatan Bongkar Muat & 694.64 & ton \\
Jarak Bongkar Muat Dari Dermaga & 3.704 & $\mathrm{~km}$ \\
Waktu Sampai Ke Area Bongkar Muat & 15 & $\mathrm{~min}$ \\
Service Speed & 8 & $\mathrm{knot}$ \\
\hline \hline
\end{tabular}

Peralatan bongkar muat yang dimaksud pada tabel 1 merupakan floating hose yang digunakan sebagai alat bongkar muat untuk kapal tanker.

\section{B. Ukuran Utama}

Ukuran utama untuk barge adalah sebagai berikut:

$\begin{array}{ll}\text { LoA } & : 43.20 \mathrm{~m} \\ \text { LPP } & : 42.156 \mathrm{~m} \\ \mathrm{~B} & : 16.00 \mathrm{~m} \\ \mathrm{H} & : 3.60 \mathrm{~m} \\ \mathrm{~T} & : 2.70 \mathrm{~m}\end{array}$

Displacement : 1695.038 ton

\section{Hambatan}

Perhitungan hambatan menggunakan metode holtrop dan menggunakan software perhitungan hambatan kapal. untuk sistem propulsi yang digunakan adalah outboard propulsion unit.

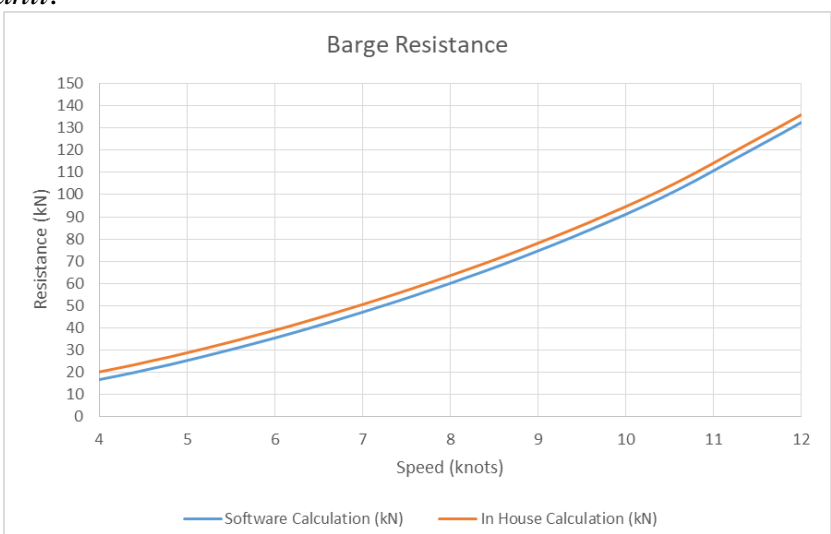

Gambar 5. Grafik Nilai Hambatan Dalam Fungsi Kecepatan Kapal.

\section{Berat Baja dan Perlengkapan Kapal}

Barge direncanakan memiliki superstructure dan deckhouse, digunakan perhitungan pendekatan sehingga menghasilkan nilai berat baja kapal seluruhnya yaitu lambung, superstructure, dan deckhouse. Perlengkapan yang ada pada barge melingkupi peralatan mooring yang terdiri dari tali tambat, bollard, dan SPUD kemudian perlengkapan 
bongkar muat yaitu winch dan crane. Didapatkan berat baja kapal sebesar 459.712 ton. Berat perlengkapan kapal 247.559 ton.

\section{E. Freeboard Barge}

Barge dalam perhitungan freeboard yang tercantum dalam ICLL merupakan termasuk ke dalam kapal tipe B [7]. Sehingga perhitungan freeboard d nlknlknnlknl9ari barge mengikuti peraturan ICLL perihal freeboard untuk kapal tipe B. Berikut merupakan rekapitulasi dari perhitungan minimum freeboard untuk barge dapat dilihat pada tabel 2 .

Tabel 2.

Minimum Freeboard

\begin{tabular}{lccl}
\hline \multicolumn{1}{c}{ Koreksi Freeboard } & $\begin{array}{c}\text { Freeboard } \\
(\mathbf{m m})\end{array}$ & \multicolumn{1}{c}{ Keterangan } \\
\hline $\begin{array}{l}\text { Standard } \\
\text { Freeboard } \\
\text { Minimum }\end{array}$ & $\mathrm{F}_{1}$ & 366 & $\begin{array}{l}\text { Dilihat pada tabel } \\
\text { freeboard kapal tipe B } \\
\text { yang tercantum pada }\end{array}$ \\
$\begin{array}{l}\text { Koreksi Fungsi } \\
\text { Panjang Kapal }\end{array}$ & $\mathrm{F}_{2}$ & 374.52 & $\begin{array}{l}\text { ICLL } \\
\text { Koreksi Fungsi }\end{array}$ \\
$\begin{array}{l}\text { C Kapal } \\
\text { Koreksi Fungsi } \\
\text { Bangunan Atas } \\
\text { Total Minimum } \\
\text { Tinggi Freeboard }\end{array}$ & $\mathrm{F}_{3}$ & 469.82 & $\begin{array}{l}\mathrm{E}=43.200 \mathrm{~m} \\
\mathrm{CB}>0.68\end{array}$ \\
\hline \hline
\end{tabular}

Setelah didapatakan semua hasil koreksi nilai freeboard, maka didapatkan besar minimum freeboard untuk kapal yang didesain, sehingga selisih $\mathrm{H}-\mathrm{T}$ harus melebihi minimum freeboard yang disyaratkan. Karena H-T barge bernilai 900 $\mathrm{mm}$, maka barge memenuhi kriteria untuk minimum freeboard.

\section{F. Stabilitas Barge}

Perhitungan stabilitas kapal pada desain ini menggunakan bantuan software untuk menghitung stabilitas kapal, dimana terdapat 3 loadcase untuk menghitung stabilitas kapal yaitu kondisi muatan penuh, kondisi tanpa DWT dan kondisi kapal Kosong.

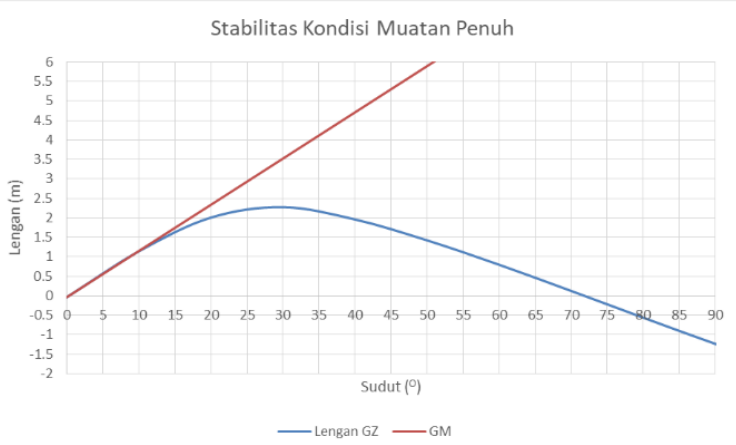

Gambar 6. Grafik Stabilitas Untuk Kondisi Muatan Penuh.

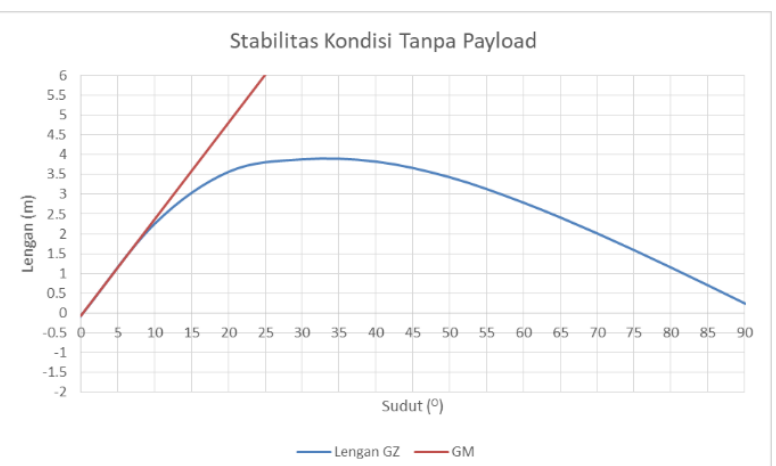

Gambar 7. Grafik Stabilitas Untuk Kondisi Tanpa Payload.

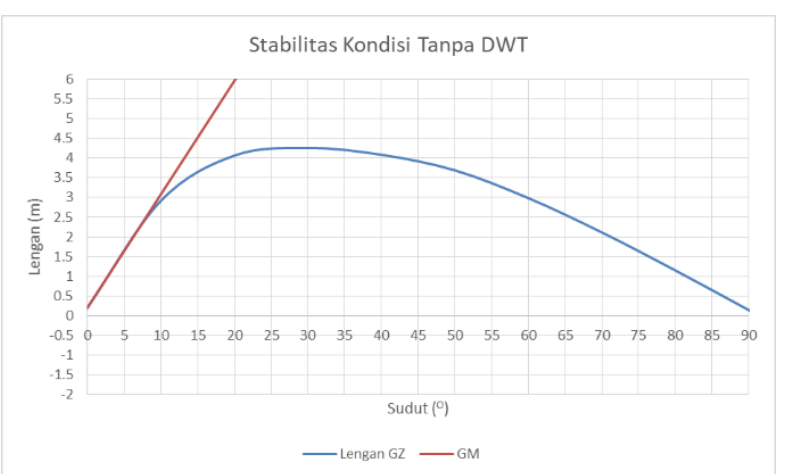

Gambar 8. Grafik Stabilitas Untuk Kondisi Kapal Kosong.

Gambar 6, Gambar 7, dan Gambar 8 menunjukkan lengan GZ dalam fungsi sudut oleng kapal, dan menunjukkan nilai inisal GM pada barge di tiap loadcase. Dari grafik dapat dilihat bahwa nilai GZ maksimum pada tiap loadcase terletak pada sudut oleng lebih dari $25^{\circ}$, mengindikasikan bahwa barge memenuhi salah satu kriteria stabilitas. Kriteria stabilitas dari barge dapat dilihat pada tabel 3 .

Tabel 3.

Pengecekan Kriteria Stabilitas Kapal

\begin{tabular}{cllll}
\hline \multicolumn{1}{c}{ Kriteria } & $\begin{array}{c}\text { Muatan } \\
\text { penuh }\end{array}$ & $\begin{array}{c}\text { Tanpa } \\
\text { Payload }\end{array}$ & $\begin{array}{c}\text { Kapal } \\
\text { Kosong }\end{array}$ & Status \\
\hline$e_{0.30^{\circ}}>=0.055 \mathrm{m.rad}$ & 0.7624 & 1.3833 & 1.6526 & Memenuhi \\
$e_{0.40^{\circ}}>=0.09 \mathrm{~m} . \mathrm{rad}$ & 1.1374 & 2.0598 & 2.3836 & Memenuhi \\
$e_{30.40^{\circ}}>=0.03 \mathrm{m.rad}$ & 0.375 & 0.6765 & 0.731 & Memenuhi \\
$h_{30^{\circ}}>=0.2 \mathrm{~m}$ & 0.2 & 3.881 & 4.256 & Memenuhi \\
$\varphi_{G Z \max }>=25 \mathrm{deg}$ & 29.1 & 33.6 & 29.1 & Memenuhi \\
$G M_{0}>=0.15 \mathrm{~m}$ & 6.759 & 13.883 & 16.683 & Memenuhi \\
\hline \hline
\end{tabular}

G. Biaya Pembangunan Barge

Perhitungan biaya pembangunan kapal meliputi total harga dari seluruh komponen kapal seperti pelat baja dan konstruksi dari barge, perlengkapan yang ada di barge seperti winch, bollard, crane, dan peralatan lainnya, harga hose, harga generator dll, kemudian akan ditambahkan margin keuntungan dari galangan. Estimasi harga pembangunan barge yaitu sebesar Rp53,978,058,950.86 atau terbilang Lima Puluh Tiga Milyar Sembilan Ratus Tujuh Puluh Delapan Juta Lima Puluh Delapan Ribu Sembilan Ratus Lima Puluh Koma Delapan Enam Rupiah. Perhitungan diatas menggunakan kurs dollar per tanggal 31 Desember 2018 dimana harga kurs \$1 yaitu Sebesar Rp14,489.00 atau terbilang Empat Belas Ribu Empat Ratus Delapan Puluh Sembilan Rupiah.

\section{H. Desain Rencana Umum}

Rencana umum merupakan desain dari ruangan dan kompartemen-kompartemen yang ada pada barge. Sesuai dengan peletakan peralatan dan perlengkapan yang ada pada barge. Rencana umum barge dapat dilihat pada gambar 13. Pada rencana umum jarak gading didesain sebesar 0.6 meter, dan barge memiliki deckhouse dan superstructure. Pembuatan desain rencana umum ini juga telah meperhitungkan area berbahaya yang ada pada kapal tanker.

\section{Desain Model 3D}

Pembuatan model dilakukan dengan menggunakan software. Desain Model 3D barge ini berfungsi untuk memberikan gambaran lebih jelas mengenai desain barge yang dibuat, desain 3D ini sudah disesuaikan dengan ukuran 
utama dari barge dan desain rencana umum, desain model 3d dapat dilihat pada gambar 10 .

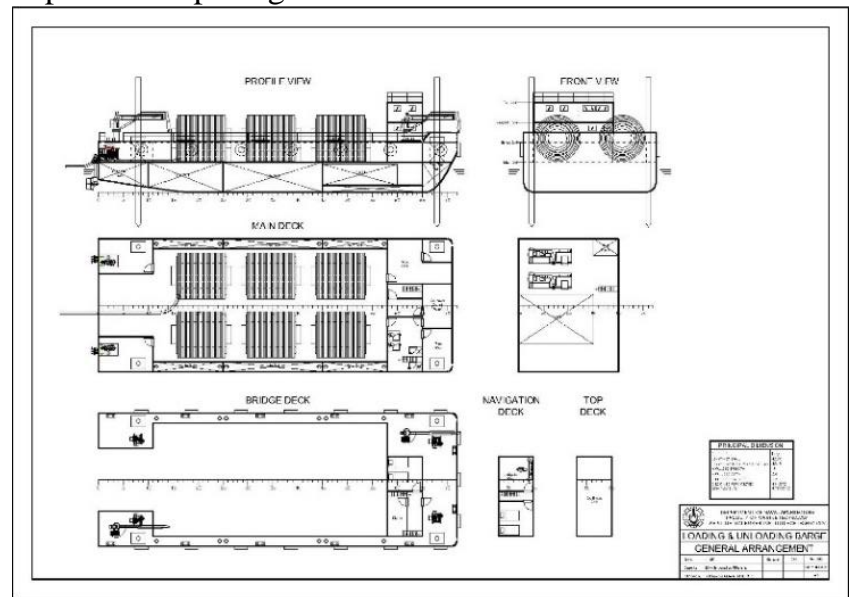

Gambar 9. Rencana Umum.
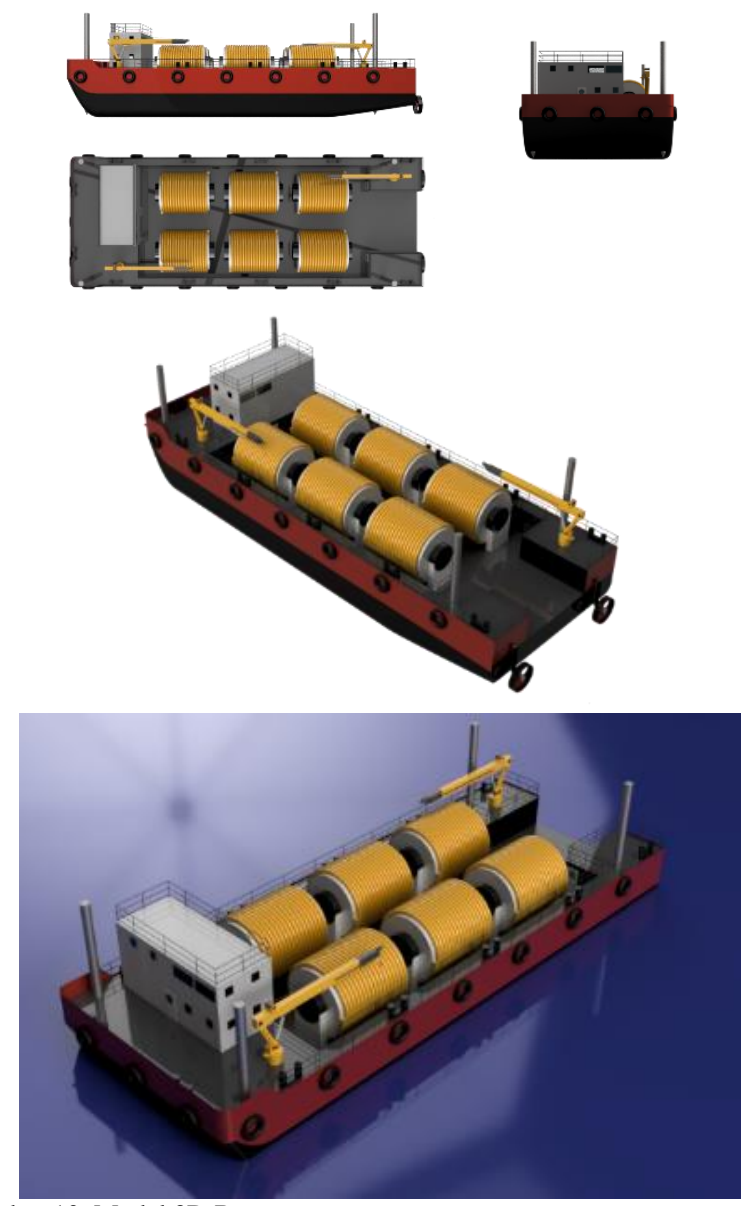

Gambar 10. Model 3D Barge.

\section{PERENCANAAN SISTEM BONGKAR MUAT}

\section{A. Penentuan Posisi Barge pada Tanker}

Posisi sandar barge saat tanker melakukan proses bongkar muat, didasari oleh proses transfer ship to ship. Barge akan bersandar pada bagian starboard tanker atau portside tanker untuk melakukan prose bongkar muat, penenutuan posisi barge ini sudah disesuiakan dengan area yang berbahay yang ada pada kapal tanker, area berbahaya yang ada pada kapal tanker dapat dilihat pada gambar 11 dan pengaturan bongkar muat dapat dilihat pada gambar 13 .

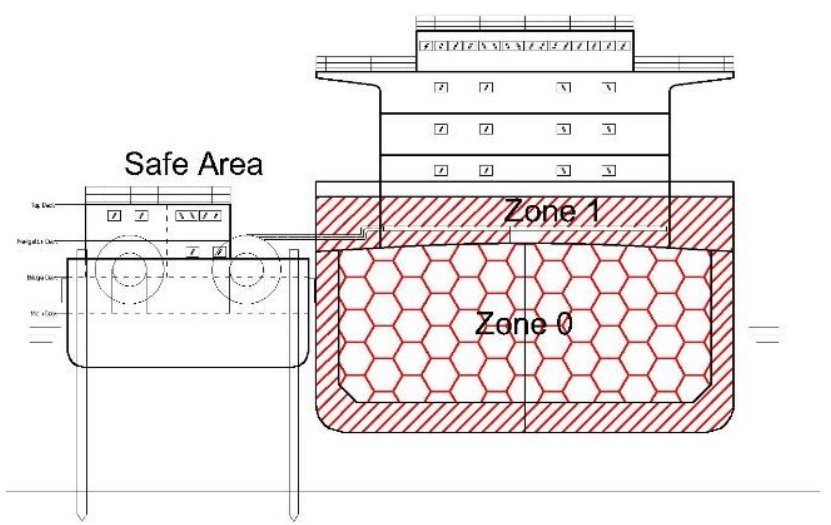

Gambar 11. Area Berbahaya pada kapal tanker.

Pada gambar 10 dapat dilihat bahwa zona 0 dan zona 1 merupakan area berbahay yang ada pada kapal tanker, dan barge berada di luar area berbahaya atau safe zone Skenario bongkar muat dari kapal tanker dengan barge adalah sebagai berikut:

1. Barge menghampiri tanker dan memposisikan diri di posisi starboard atau portside kapal tanker

2. Barge menyalurkan tali tambatnya ke kapal tanker, karena barge akan mendekat secara perlahan lahan dengan ditarik menggunakan tali tambat

3. Barge mendekat perlahan-lahan, hingga barge menempel pada pelat sisi tanker

4. Kemudian barge ditali pada bollard yang ada pada tanker

5. Kemudian barge akan menjatuhkan SPUD atau pile agar barge berada dalam kondisi stabil, sehingga pemasangan hose dari barge ke tanker mudah

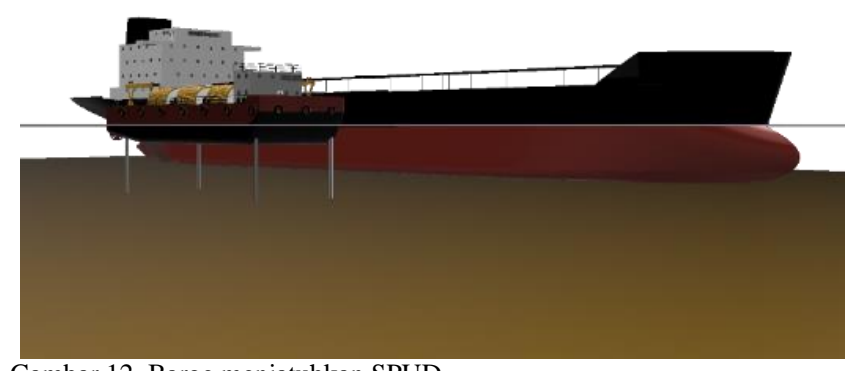

Gambar 12. Barge menjatuhkan SPUD.

6. Dilanjutkan dengan pemasangan hose dari barge ke tanker, dengan menggunakan crane, bisa dilakukan dengan crane milik barge ataupun crane milik kapal tanker

7. Kemudian menunggu hingga proses bongkar muat selesai

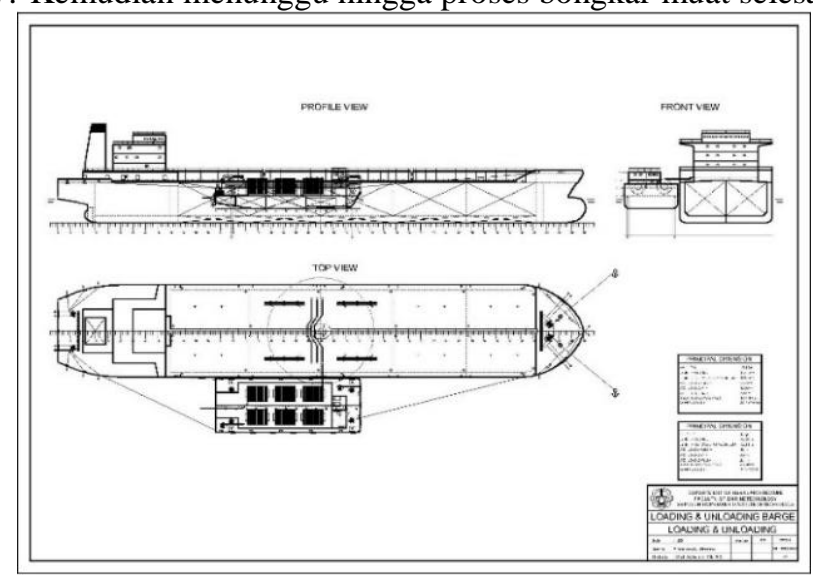

Gambar 13. Posisi Barge saat Tangker Bongkar Muat. 


\section{B. Mooring System}

Mooring sistem yang digunakan untuk barge adalah mooring yang dapat membuat barge menjadi benda statis, sehingga hampir tidak mengalami gerakan akibat arus air atau angin. Mooring yang dipilih adalah jenis mooring pile dengan menggunakan SPUD atau pile yang biasa dipakai pada barge yang membutuhkan kestabilan tinggi. Untuk menetukan ukuran SPUD perlu diketahui gaya gaya yang terjadi pada kapal tanker dan SPUD.

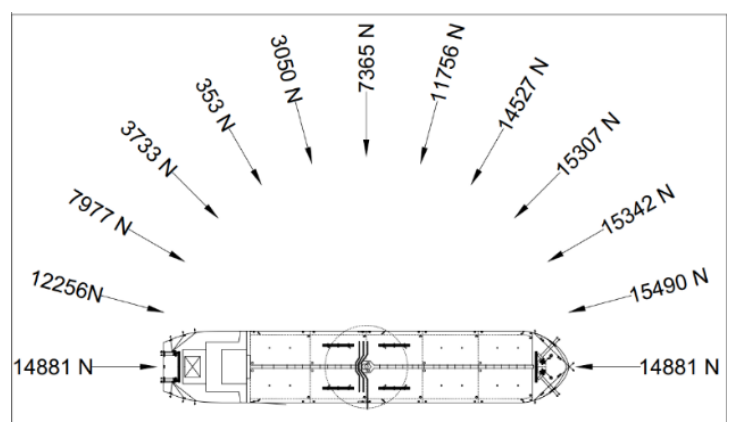

Gambar 14. Beban Pada Kapal Tanker.

Kapal tanker medapatkan gaya dari arus air dan arus angin padaa saat kapal tanker melakukan lego jangkar. Dan beban terbesar dihitung pada saat kondisi ekstrim, yaitu gaya minimum sebesar $31 \mathrm{kN}$. Pada SPUD terjadi beban hidrostatik akibat kedalaman air laut. Kemudian gaya yang terjadi pada kapal tanker dan gaya hidrostatik dijumlahkan sehingga menghasilkan nilai gaya total yang terjadi pada SPUD. SPUD yang didesain memiliki diameter sebesar $609.6 \mathrm{~mm}$. Sehingga untuk mengetahui tegangan yang terjadi pada SPUD maka gaya total dibagi dengan luas penampang SPUD sehingga menghasilkan nilai sebesar $3,887 \times 10^{7} \mathrm{~Pa}$. Dan tegangang izin maksimum sebesar $2,08 \times 10^{8} \mathrm{~Pa}$.

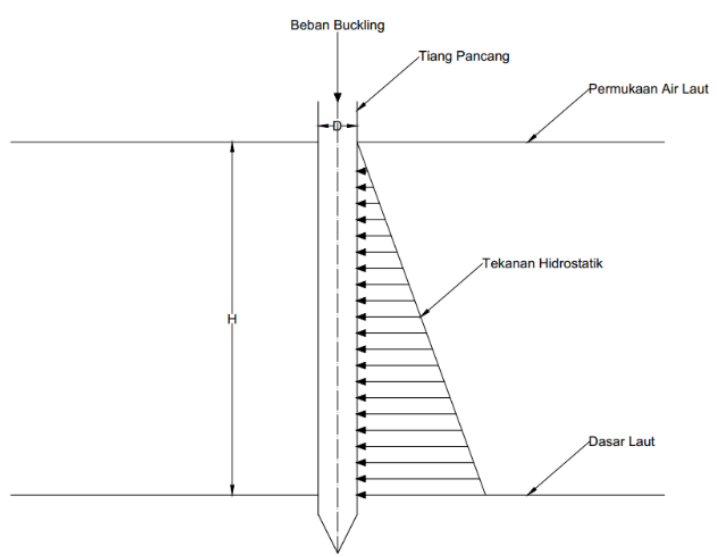

Gambar 15. Beban Yang Terjadi Pada SPUD

\section{Arrangement Dengan Dermaga}

Pengaturan bongkar muat dengan dermaga berfungi untuk memberikan gambaran bagaimana pengaturan bongkar muat dengan dermaga. Pengaturan yang dimaksud yaitu sambungan dari shore connection menuju cargo manifold, shore connection dari dermaga akan disambung dengan floating hose dan hose akan menjulur sampai ke daerah bongkar muat dan disambungkan pada cargo manifold yang ada pada kapal tanker. Sehingga ada 3 cara bongkar muat yaitu bongkar muat dengan jetty, bongkar muat dengan barge, dan bongkar muat dengan jetty dan barge, gambaran dari ketiga pengaturan tersebut dapat dilihat pada gambar 16, gambar 17, dan gambar 18.

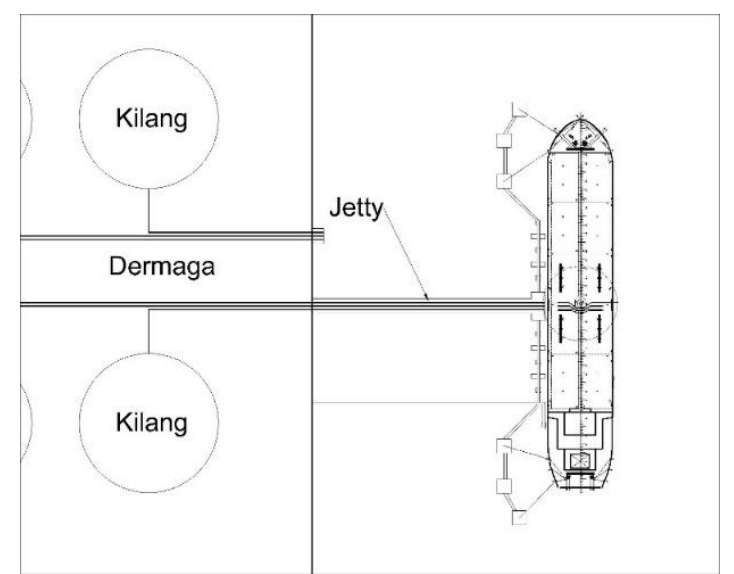

Gambar 16. Pengaturan Kapal Tanker dengan Jetty.

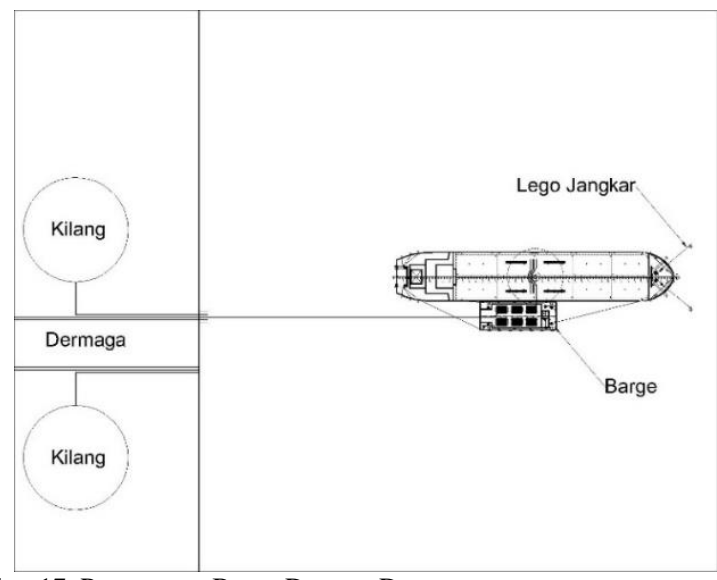

Gambar 17. Pengaturan Barge Dengan Dermaga.

Dari gambar 16 dapat dilihat bahwa jetty berfungis sebagai penghubung antara kapal tanker dengan dermaga, dimana muatan curah kapal tanker disalurkan menggunakan pipa permanen yang dipasang pada jetty, ini merupakan pegaturan bongkar muat pada kapal tanker pada umumnya. Sedangkan gambar 17 menunjukkan pengaturan barge dengan dermaga, dimana floating hose yang terdapat pada barge sisambungkan dengan shore connection yang ada pada dermaga dan floating hose akan menjulur sejauh daerah bongkar muat dan pada gambar 18 menunjukkan kombinasi bongkar muat dengan jetty dan dengan barge hal ini berfungsi unutk mempercepat proses bongkar muat dengan cara mengurangi antrian bongkar muat, dimana kapal yang tidak bisa bersandar pada jetty dapat melakukan bongkar muat dengan menggunkana barge, kombinasi ini cocok digunakan di dermaga dermaga migas yang memiliki traffic pelayaran yang cukup padat dan ramai.

\section{KESIMPULAN}

Setelah dilakukan proses desain didapatkan kesimpulan sebagai berikut:

1. Diperoleh ukuran utama barge Sebagai berikut:
LoA $\quad: 43.20 \mathrm{~m}$
LPP $\quad: 42.16 \mathrm{~m}$
B $: 16.00 \mathrm{~m}$
$\mathrm{H} \quad: 3.60 \mathrm{~m}$
$\mathrm{T} \quad: 2.70 \mathrm{~m}$

Displacement : 1695.038 ton

Vs : $8 \mathrm{knot}$

Propulsion : 2 x $225 \mathrm{~kW}$, electric outboard engine

Payload : 696.64 ton 
2. Harga pembangunan barge sebesar Rp53,978,058,950.86, sehingga dapat disimpulkan harga pembangunan barge jauh lebih murah dibandingkan harga pembangunan Jetty.

3. Barge yang didesain dapat menggantikan fungsi jetty sebagai sarana bongkar muat kapal tanker.

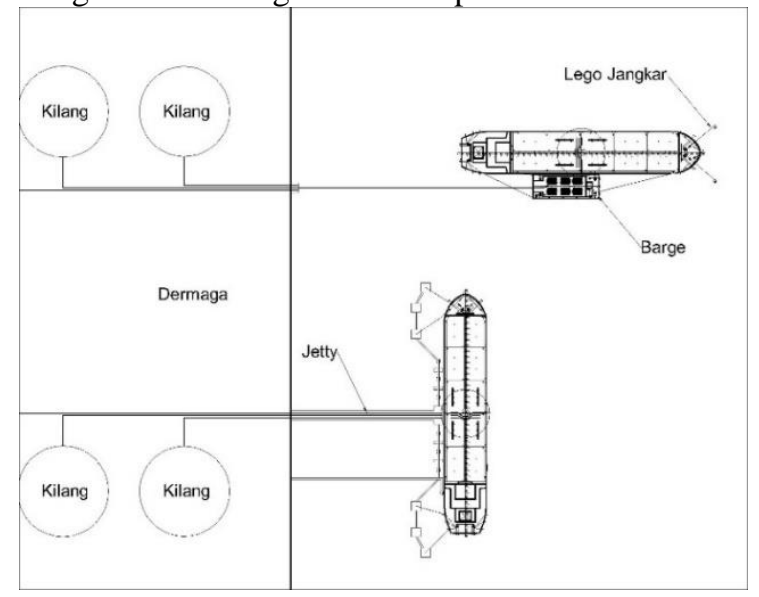

Gambar 18. Bongkar Muat Kombinasi Barge dan Jetty.

\section{DAFTAR PUSTAKA}

[1] M. Mulyono, "Keberlangsungan visi maritim indonesia pada tahun 2019," Surabaya, 2019.

[2] Y. Islamia, F. Fuddoly, and H. Wahyudi, "Perencanaan dermaga kapal tanker 100.000 DWT pada terminal untuk kepentingan sendiri (TUKS) UP III pt. pertamina di pulau sambu, batam," Institut Teknologi Sepuluh Nopember, 2013.

[3] K. McConnell and W. Allsop, Piers, jetties and related structure exposed to waves. London: Thomas Telford Publishing, 2004.

[4] R. Raunek, "How single point mooring (spm) offshore operation works?," Marine Insight, 2013. [Online]. Available: https://www.marineinsight.com/offshore/how-single-point-mooringspm-offshore-operation-works/amp/.

[5] S. Zhao, "Risk modeling of dp operation fore offshore tandem offloading," Norwegian University of Science Technology, 2016.

[6] A. Anish, "What is ship-to-ship transfer (sts) and requirements to carry out the same?," Marine Insight, 2016. [Online]. Available: https://www.marineinsight.com/maritime-law/what-is-ship-to-shiptransfer-sts-and-requirements-to-carry-out-the-same/

[7] IMO, International Convention on Load Lines. London: Lloyd's Register, 1966 